\title{
Competitive advantage of a dengue 4 virus when co-infecting the mosquito Aedes aegypti with a dengue 1 virus
}

\author{
Marie Vazeille1, Pascal Gaborit², Laurence Mousson', Romain Girod ${ }^{2}$ and Anna-Bella Failloux ${ }^{1 *}$
}

\begin{abstract}
Background: Dengue viruses (DENV) are comprised in four related serotypes (DENV-1 to 4) and are critically important arboviral pathogens affecting human populations in the tropics. South American countries have seen the reemergence of DENV since the 1970's associated with the progressive re-infestation by the mosquito vector, Aedes aegypti. In French Guiana, DENV is now endemic with the co-circulation of different serotypes resulting in viral epidemics. Between 2009 and 2010, a predominant serotype change occurred from DENV-1 to DENV-4 suggesting a competitive displacement. The aim of the present study was to evaluate the potential role of the mosquito in the selection of the new epidemic serotype.

Methods: To test this hypothesis of competitive displacement of one serotype by another in the mosquito vector, we performed mono- and co-infections of local Ae. aegypti collected during the inter-epidemic period with both viral autochthonous epidemic serotypes and compared infection, dissemination and transmission rates. We performed oral artificial infections of F1 populations in BSL-3 conditions and analyzed infection, dissemination and transmission rates.

Results: When two populations of Ae. aegypti from French Guiana were infected with either serotype, no significant differences in dissemination and transmission were observed between DENV-1 and DENV-4. However, in co-infection experiments, a strong competitive advantage for DENV-4 was seen at the midgut level leading to a much higher dissemination of this serotype. Furthermore only DENV-4 was present in Ae. aegypti saliva and therefore able to be transmitted.

Conclusions: In an endemic context, mosquito vectors may be infected by several DENV serotypes. Our results suggest a possible competition between serotypes at the midgut level in co-infected mosquitoes leading to a drastically different transmission potential and, in this case, favoring the competitive displacement of DENV-1 by DENV-4. This phenomenon was observed despite a similar replicative fitness in mono-infections conditions.
\end{abstract}

Keywords: Dengue, Aedes aegypti, Co-infection, Competitive interactions

\section{Background}

Dengue viruses (DENV) are critically important arboviral pathogens responsible for an estimated 50-100 million cases of dengue (DEN) and 500,000 cases of the more severe and sometimes fatal dengue hemorrhagic fever/shock syndrome (DHF/DSS syndromes) annually (reviewed in [1]). DENV is a single-stranded positive sense RNA virus belonging to the genus Flavivirus

\footnotetext{
*Correspondence: anna-bella.failloux@pasteur.fr

${ }^{1}$ Institut Pasteur, Department of Virology, Arboviruses and Insect Vectors, 25 rue du Dr Roux, 75724 Paris Cedex 15, France

Full list of author information is available at the end of the article
}

(family Flaviviridae). Each of four related serotype (DENV-1 to 4) is anti-genetically distinct, comprised multiple lineages [2] and requires mosquitoes to complete their transmission to a vertebrate host. Although improved clinical care has reduced case fatality rates, there are currently no specific antiviral therapies or commercial vaccines.

In endemic regions where all four DENV serotypes are present, varying predominance of each serotype has been observed from year to year. The development of air travels has facilitated rapid displacements of viremic patients and has led to the introduction of multiple 
DENV into new endemic locations where increased disease severity has been linked to the displacement and extinction of local lineages [3-7]. Extinction and emergence of new virus lineages can be attributed to stochastic events associated with genetic bottlenecks in the viral population size $[4,5,8,9]$. Bottlenecks may be caused by spatio-temporal reduction in vector population sizes and/ or as a consequence of increase in human herd immunity [7]. Alternatively, predominant lineage change can be also attributed to differential fitness for transmission as was evidenced firstly by the higher susceptibility of Aedes aegypti for the invading Asian DENV genotypes than for the American genotype it has displaced in some locations [10]. Other examples of predominant lineage change events have been documented at more regional scales $[5,7,9,11-14]$. Predominant lineage change can be attributed to deleterious mutations which lead to a progressive elimination of a lineage by purifying selection $[8,12,15$, 16]. Moreover, other factors related to the vectors can be implicated; some genotypes appear to be less well transmitted by local vector species [10, 13, 17-20]. Replication efficiency of certain strains in the human host may induce higher viremias which in turn, better infect mosquitoes [21, 22]. Additionally, the outcome of infection can depend on the specific pairing of vector and pathogen genotypes through genotype-by-genotype $(\mathrm{G} \times \mathrm{G})$ interactions [23].

Following World War II, no dengue outbreaks were reported in the Americas while epidemics repeatedly struck countries in Southeast Asia. This reduction was mainly due to the eradication program initiated by the Pan American Health Organization (PAHO) to control the mosquito Ae. aegypti. Disruption of the program in the early 1970s however allowed a progressive reinfestation by Ae. aegypti [24]. In French Guiana, DEN became endemic with epidemics occurring every 4-6 years [25] and the first cases of DHF being reported during the 1991-92 DENV-2 outbreak [26]. While these outbreaks often coincided with the co-circulation of different serotypes [27], a predominant serotype change occurred from DENV-1 to DENV-4 between 2009 and 2010 [28] suggesting a competitive displacement, a phenomenon commonly observed among DENV genotypes [29] and serotypes [5, 7].

While competitive displacement among DENV strains has traditionally been examined through the ability of newly introduced strains to better replicate in human host, replication efficiency in the mosquito vector has remained poorly understood $[10,19,30,31]$. Coinfection of vectors by multiple DENV strains occurs in nature and has been well documented in Ae. aegypti populations from both Thailand [32] and Brazil [33], occurring either when the mosquito takes several bloodmeals from hosts infected with different serotypes, or when it takes a blood-meal from a single co-infected host [34-37].

Here, we have addressed the question of whether a newly introduced DENV-4 strain can successfully out-compete a well-established DENV-1 strain during co-infection in two populations of Ae. aegypti collected in French Guiana using in vivo experimental infections. We examined the ability of both DENV strains to overcome the different physical barriers (midgut and salivary glands) and subsequently, be transmitted successfully through saliva.

\section{Methods}

\section{Viruses and cells}

DENV-1 and DENV-4 isolates were provided by the French National Reference Center for Arboviruses (Institut Pasteur of French Guiana); viruses were isolated from sera collected in 2009 from patients living in the city of Cayenne by two successive passages in mosquitoes by intrathoracic inoculation. After a 14-days period of incubation at $28{ }^{\circ} \mathrm{C}$, mosquitoes inoculated with the sera were triturated in heated $\left(56{ }^{\circ} \mathrm{C}\right.$ for $\left.30 \mathrm{~min}\right)$ FCS (Fetal Calf Serum) and the resulting supernatant used again for a second mosquito passage. The final supernatant was then passaged on Ae. albopictus C6/36 cells for production of the viral stocks.

Aedes albopictus cells (C6/36) were maintained in Leibowitz L-15 medium with $1 \%$ non-essential aminoacids (Invitrogen), $10 \%$ fetal bovine serum (FBS) and $1 \%$ penicillin/streptomycin (P/S) (Invitrogen).

\section{Mosquitoes}

Mosquito samples were fortuitously collected in December 2009 during the inter-epidemic period (after the DENV-1 and before DENV-4 outbreaks) in the city of Cayenne, French Guiana: one in an environment of dense housing "Center" (CEN) and one in an environment of scattered housing, "Madeleine" (MAD). The samples collected as larvae and pupae were brought back to the laboratory and reared until the adult stage (F0 generation) at $28 \pm 1{ }^{\circ} \mathrm{C}$ with $80 \%$ relative humidity and a $16 \mathrm{~h}: 8 \mathrm{~h}$ photoperiod. Ae. aegypti adults were sorted, fed with $10 \%$ sucrose solution, and blood-fed every two days to obtain eggs (F1 generation). Egg batches were then sent to the Institut Pasteur in Paris where larvae were reared to adult stage under standardized conditions (temperature: $26{ }^{\circ} \mathrm{C} \pm 2{ }^{\circ} \mathrm{C}$, relative humidity: $80 \% \pm 10 \%$, photoperiod: $12 \mathrm{~h}: 12 \mathrm{~h}$ ) in pans with tap water and yeast tablets. F1 females were used for experimental oral infections under BSL-3 conditions.

The Paea strain of Ae. aegypti provided by the Institut Louis Malardé (Tahiti, French Polynesia) and reared in Paris since 1994, was used for intrathoracic inoculation to isolate and amplify DENV strains. 


\section{Mosquito experimental infection and viral dissemination} Infection assays were performed with 7 day-old females which were allowed to feed for $15 \mathrm{~min}$ through a chicken skin membrane covering the base of a glass feeder containing the blood-virus mixture maintained at $37{ }^{\circ} \mathrm{C}$. The infectious blood-meal was composed of a virus suspension diluted (1:3) in washed rabbit erythrocytes isolated from arterial blood collected $24 \mathrm{~h}$ before the infectious blood-meal. To attract females to the glass feeder, ATP was added to the blood-meal at a final concentration of $5 \times 10^{-3} \mathrm{M}$. Completely engorged females were kept in small cardboard containers and maintained with $10 \%$ sucrose at $28 \pm 1{ }^{\circ} \mathrm{C}$ for $14-21$ days. Titers of the blood-meal were $10^{5}$ or $10^{6} \mathrm{ffu} / \mathrm{mL}$ for mono-infected meals and $10^{6} \mathrm{ffu} / \mathrm{mL}$ for each virus in co-infected meals.

For mosquitoes fed with a single serotype, dissemination status was determined via indirect immunofluorescent assay (IFA) on head squashes [38]. Dissemination efficiency represents the proportion of mosquitoes where the virus has successfully penetrated the midgut and subsequently colonized secondary organs and tissues (i.e., positive by IFA on head squashes). Mosquitoes inoculated with DENV-1 or DENV-4 were used as positive controls. Negative controls were mosquitoes inoculated with cell culture media.

For mosquitoes fed with both DENV serotypes, the infection, dissemination and transmission status were determined by qRT-PCR using primers specific to the capsid gene: D1-Lm/C/153/+ (GAG AAA CCG CGT GTC AAC TG) and TS2-Lm/C/219/- (GGA AAC GAA GGA ATG CCA CC). A standard curve was generated using duplicates from $10^{2}$ to $10^{8}$ copies of RNA synthetic transcripts per reaction [39]. Infection efficiency corresponds to the proportion of mosquitoes with an infected abdomen (thus an infected midgut). Sensitivity of the qRT-PCR for both serotypes was asserted by analyzing mosquitoes infected intra-thoracically by one serotype.

Transmission assessed with saliva collection and titration At 14 or 21 days post-infection (dpi), surviving mosquitoes were chilled, and their wings and legs removed. Proboscis was inserted into a filter tip containing $5 \mu \mathrm{L}$ FCS for $45 \mathrm{~min}$. Serum containing the saliva was expelled under pressure into a $1.5 \mathrm{~mL}$ tube containing $45 \mu \mathrm{L}$ Leibovitz L15 medium supplemented with $10 \%$ FCS. For mono-infected mosquitoes, $40 \mu \mathrm{L}$ of this sample were added to monolayers of C6/36 cells in 96-well plates. Infectious particles were detected by the foci forming technique using an immunofluorescent assay.

DENV-infected cells were incubated 5 days at $28{ }^{\circ} \mathrm{C}$ under an overlay consisting of $50 \%$ of Leibovitz L-15 medium supplemented with $5 \%$ FCS and $50 \%$ of carboxyl methyl cellulose (CMC). Cells were fixed with $3.6 \%$ formaldehyde at room temperature (RT) for $20 \mathrm{~min}$ and foci were detected by IFA.

For mosquitoes co-infected with the two serotypes of DENV, saliva was collected at $21 \mathrm{dpi}$ to enhance the transmission rate and the whole sample $(50 \mu \mathrm{L})$ was added to a monolayer of C6/36 cells in a 96-well plaque. After an incubation of 6 days, the supernatant was collected for RNA extraction (Nucleospin Tissue XS Macherey-Nagel) and analyzed by qRT-PCR to quantify RNA from each serotype. The cells were then fixed with $3.6 \%$ formaldehyde and treated as described above to assert infectivity.

\section{Immunofluorescence assay}

After a first incubation of 4 min with PBS $+0.5 \%$ Triton X-100 (Sigma) at RT and three washes in PBS, cells were incubated $120 \mathrm{~min}$ at RT with a mouse ascitic fluid (provided by the French National Reference Center for Arbovirus, Institut Pasteur Paris) at a dilution of 1:100. After three washes with PBS, cells were incubated $60 \mathrm{~min}$ at RT with fluoresceine-conjugated goat antimouse IgG antibody (Biorad) at a 1:80 dilution in PBS $1 X$. After a final wash in PBS, foci were counted under a fluorescent light. The titer of infectious particles per saliva was expressed as ffu/saliva. Transmission rate corresponds to the proportion of mosquitoes with infectious saliva among mosquitoes able to disseminate the virus beyond the midgut barrier.

\section{Statistical analysis}

To detect significant differences in infection, dissemination efficiencies and transmission rates among experimental groups, comparisons were done using the Fisher's exact test (Stata software, StataCorp LP, Texas, and USA).

\section{Results}

\section{Mono-infections of mosquitoes}

To test whether competitive displacement of DENV-1 by DENV-4 can be attributed to variations in vector competence, we evaluated the ability of both DENV serotypes to be transmitted by $A e$. aegypti in monoinfected blood-meals. The presence of virus in the head and in the saliva was used to measure viral dissemination and transmission, respectively. We orally infected two populations of Ae. aegypti (CEN and MAD) with either $10^{5}$ or $10^{6} \mathrm{ffu} / \mathrm{mL}$ of each serotype and determined viral dissemination rates at 14 dpi (Fig. 1a). Dissemination efficiencies increased significantly with the blood-meal titer $(p<0.05)$ and remained roughly similar regardless of virus (DENV-1, DENV-4) or mosquito population (CEN, MAD) $(p>0.05)$.

We next examined viral dissemination and transmission at 8,10 and $14 \mathrm{dpi}$ with a blood-meal provided at a titer of $10^{6} \mathrm{ffu} / \mathrm{mL}$ (Fig. 1b, 1c). Dissemination efficiencies were 


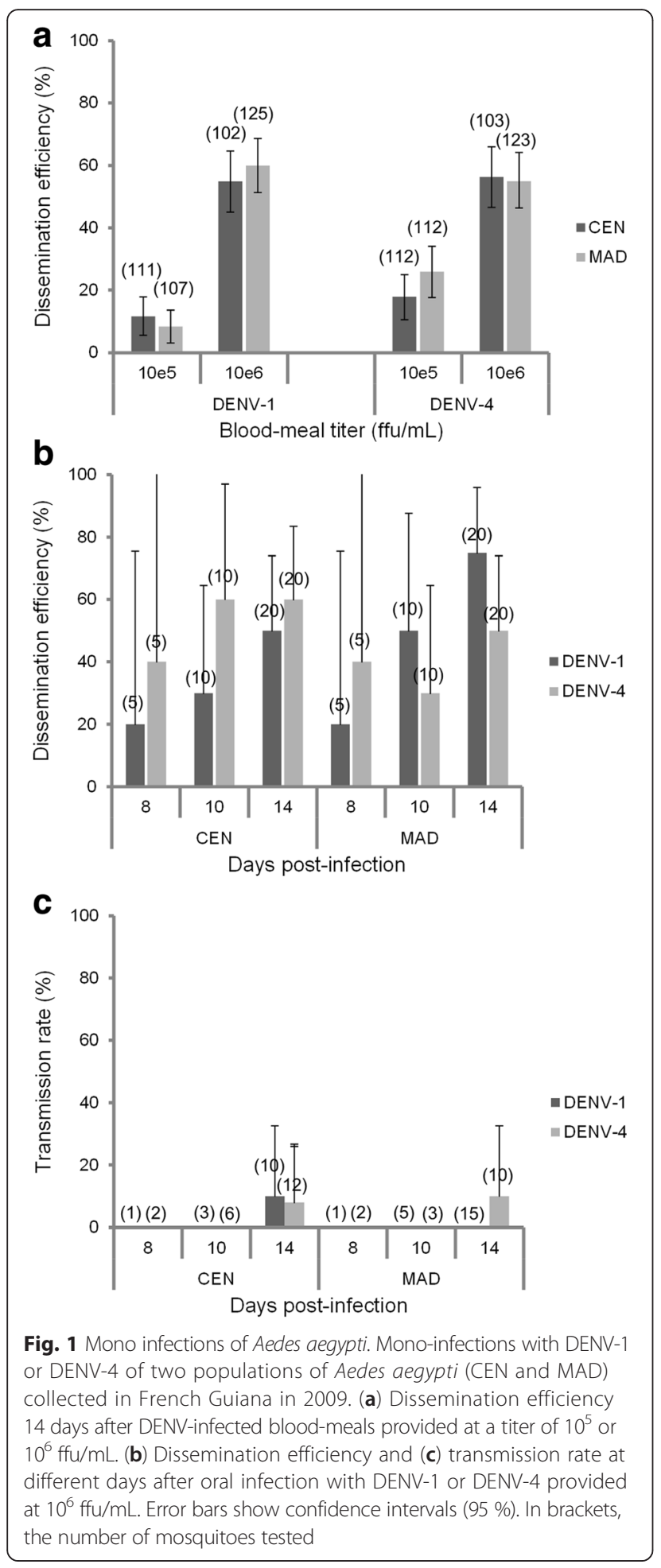

similar for both mosquito populations in all cases (by varying the day pi and the DENV) $(p>0.05)$. Assessment of transmission ability showed that less than $10 \%$ of mosquitoes with disseminated infection were able to transmit DENV at 14 dpi (Fig. 1c). These results suggest that the extrinsic incubation period was between
10 and 14 dpi regardless of mosquito population or DENV serotype.

These findings suggest that there are no significant differences in dissemination or transmission rates between mosquito populations mono-infected with either DENV1 or DENV-4.

\section{Co-infections of mosquitoes}

To determine if co-infection with two different DENV serotypes can affect vector competence, we analyzed viral infection, dissemination and transmission rates at $21 \mathrm{dpi}$, in co-infected Ae. aegypti CEN (Fig. 2). For each mosquito, saliva was collected then body (for infectious status) and head (for dissemination status) processed. Among 24 mosquitoes co-infected with both viruses, we found that at $21 \mathrm{dpi}$, more mosquitoes were infected at DENV-4 (83.3 \% \pm 16.1$)$ than with DENV-1 $(12.5 \%$ $\pm 14.4) \quad(p<0.05)$. Mosquitoes detected positive for DENV-1 were all also positive for DENV-4. When examining the proportion of mosquitoes able to disseminate the virus beyond the midgut barrier after infection, dissemination was complete and similar for both DENV serotypes $(p>0.05): 100 \%$ when examining DENV-1 (3 mosquitoes ensuring viral dissemination among 3 infected) and DENV-4 (20 mosquitoes ensuring viral dissemination among 20 infected). The 3 mosquitoes having disseminated DENV-1 had also disseminate DENV-4. Then, when analysing the transmission by detecting the virus in saliva of mosquitoes able to disseminate efficiently the virus, we showed that DENV-4 was detected in $35 \%$ $( \pm 10.9)$ of mosquitoes $(7$ mosquitoes able to transmit among 20 able to disseminate DENV-4). However, DENV-1 was not recovered from any mosquito saliva. In brief, from 24 F1 mosquitoes having received a coinfected blood-meal with DENV-1 and DENV-4, 7 were

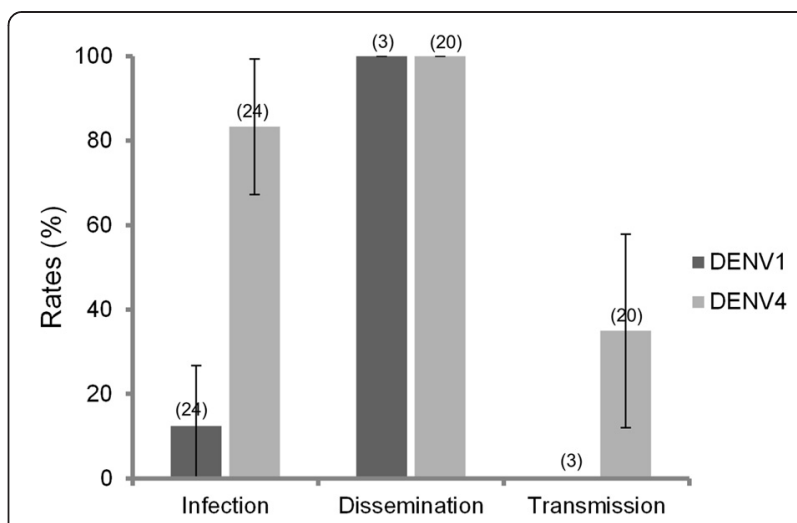

Fig. 2 Coinfection of Aedes aegypti. Infection, dissemination and transmission rates in Ae. aegypti CEN population, 21 days after oral exposure to co-infected blood-meal DENV-1/DENV-4 provided at $10^{6} \mathrm{ffu} / \mathrm{mL}$ for each virus. Viral RNA was detected by qRT-PCR. Error bars show confidence intervals (95\%). In brackets, the number of mosquitoes tested 
able to transmit DENV-4 and none DENV-1. Taken together, these findings show that DENV-4 possesses a strong competitive advantage in co-infected mosquitoes at late dpi.

\section{Discussion}

In situations where multiple DENV serotypes co-circulate, viral competition is most likely to occur in vectors where infection persists for life. In comparison, infection tends to be transient in vertebrate hosts, and is typically cleared by the host immune response. In French Guiana, DENV-4 has progressively displaced DENV-1 during the inter-epidemic period in 2009-2010. Using field-collected mosquitoes and low-passaged DENV, we showed that when mosquitoes were infected with either DENV-1 or DENV-4, no significant difference was observed in infection, dissemination or transmission rates. However, co-infection of mosquitoes with both the native DENV-1 and the newly introduced DENV-4 showed that DENV-4 possessed a strong fitness advantage compared to DENV-1.

In our experimental protocol based on co-infections with DENV-1 and DENV-4 provided at equal titers, the number of mosquito midguts infected with DENV-4 at 21 dpi was higher that the number of mosquito midguts infected with DENV-1. After having crossed the midgut, both DENV presented similar abilities to infect secondary internal organs. Critically, only DENV-4 was detected in saliva, confirming the selective advantage of DENV-4 during co-infection. During mono-infections in mosquitoes, the advantage of DENV-4 over DENV-1 was not observed.

Co-infections can lead to unique interactions requiring all aspects of the replication machinery. Examples include production of recombinant viral particles which may escape detection. This phenomenon has been previously reported within DENV serotypes, but appears to be a rare event [40-44]. Another potential interaction is that entire sections of the viral genome can be deleted followed by the replication of the remaining partial genome via complementation during co-infection with another functional virus. These defective interfering (DI) viral particles containing large genomic deletions may reduce the yield of fully functional DENV virions [45]. Once dissemination is completed, the virus reaches the salivary glands before being excreted in mosquito saliva. Only DENV-4 was detected in mosquito saliva at a proportion of $35 \%$. These results underline the importance of the midgut and the salivary glands where coinfection with both viruses has favoured DENV-4.

Co-infection of Ae. aegypti by different DENV serotypes can be described in nature, e.g. in Thailand [32], Brazil [33]. It can occur by feeding on a patient co-infected by two different serotypes [32, 34, 36, 37, 46, 47]. Our results show that in co-infected conditions, DENV-4 exhibited better transmission rates in mosquitoes and provide a potential explanation for the competitive displacement of DENV-1 by DENV-4 which occurred between 2009 and 2010 in French Guiana [28]. This finding is quite similar to the one observed in humans with live-attenuated tetravalent vaccine where replication of individual serotypes appears to be sensitive to the identity and concentration of co-infecting serotypes [48]. If one serotype is more likely to divert the replication machinery to its advantage in a co-infected mammalian cell, then more viral particles of this serotype and consequently, more neutralizing antibodies would be produced. This unbalanced immune response in hosts may result in an ineffective vaccine. Therefore, design of tetravalent vaccine should take into account interactions between serotypes.

Finally, viral displacements due to emerging epidemic events are often described; they should be closely studied using mixed infections models and not only single-strain infections that cannot reflect the outcomes of in vivo viral competition.

\section{Conclusions}

We provided evidence of a competitive advantage of a DENV serotype on another using mosquitoes from the field and two autochthonous epidemic viral strains. This finding, along with other factors such as herd immunity in the human population, could have contributed to the switch from DENV-1 to DENV-4 in 2009-2010 in French Guiana. Other emerging events involving viral displacement should be carefully studied to estimate the frequency of such events.

\section{Abbreviations}

ATP, adenosine triphosphate; CMC, carboxyl methyl cellulose; DEN, dengue; DENV, dengue virus; DENV-1, dengue serotype 1; DENV-2, dengue serotype 2; DENV-4: dengue serotype 4; DHF, dengue hemorrhagic fever; dpi, day postinfection; DSS, dengue shock syndrome; FBS, fetal bovine serum; FCS, fetal calf serum; ffu, fluorescent focus forming units; IFA, indirect immunofluorescent assay; P/S, penicillin/streptomycin; PAHO, Pan American Health Organization; PBS, phosphate-buffered saline; qRT-PCR: quantitative Reverse transcription polymerase chain reaction; $\mathrm{RNA}$, ribonucleic acid; $\mathrm{RT}$, room temperature

\section{Acknowledgments \\ We wish to thank Philippe Desprès and Philippe Dussart for providing viral strains and reagents and Henri Jupille for his contribution in correcting the manuscript. \\ Funding \\ PG's stay in Paris was supported by the Regional Health Agency in French Guiana "Convention n09-21/GRSP du 10 août 2009". This study was funded by the Institut Pasteur and the French Government's Investissement d'Avenir program, Laboratoire d'Excellence "Integrative Biology of Emerging Infectious Diseases" (grant nANR-10-LABX-62-IBEID).}

Availability of data and materials

All the data supporting our findings is contained within the manuscript. 


\section{Authors' contributions}

MV participated in the design of the study and drafting the manuscript, performed mosquito experimental infections. PG and RG participated in mosquito collections. LM performed molecular analysis. ABF participated in the design of the study, performed the statistical analysis and drafted the manuscript. All authors read and approved the final manuscript.

\section{Competing interests}

The authors declare that they have no competing interests.

\section{Consent for publication}

Not applicable.

\section{Ethics approval and consent to participate}

The Institut Pasteur animal facility has received accreditation from the French Ministry of Agriculture to perform experiments on live animals in compliance with the French and European regulations on care and protection of laboratory animals. This study was approved by the Institutional Animal Care and Use Committee (IACUC) at the Institut Pasteur. No specific permits were required for the described field studies in locations which are not protected in any way and did not involve endangered or protected species.

\section{Author details}

${ }^{1}$ Institut Pasteur, Department of Virology, Arboviruses and Insect Vectors, 25 rue du Dr Roux, 75724 Paris Cedex 15, France. ${ }^{2}$ Medical Entomology Unit, Institut Pasteur of French Guiana, Cayenne, French Guiana.

\section{Received: 12 November 2015 Accepted: 14 June 2016}

\section{Published online: 08 July 2016}

\section{References}

1. Vasilakis N, Weaver SC. The history and evolution of human dengue emergence. Adv Virus Res. 2008;72:1-76.

2. Holmes EC, Twiddy SS. The origin, emergence and evolutionary genetics of denque virus. Infect Genet Evol. 2003;3(1):19-28.

3. Carrington CV, Foster JE, Pybus OG, Bennett SN, Holmes EC. Invasion and maintenance of dengue virus type 2 and type 4 in the Americas. J Virol. 2005;79(23):14680-7.

4. Diaz FJ, Black WC, Farfan-Ale JA, Lorono-Pino MA, Olson KE, Beaty BJ. Dengue virus circulation and evolution in Mexico: a phylogenetic perspective. Arch Med Res. 2006;37(6):760-73.

5. Myat Thu H, Lowry K, Jiang L, Hlaing T, Holmes EC, Aaskov J. Lineage extinction and replacement in dengue type 1 virus populations are due to stochastic events rather than to natural selection. Virology. 2005;336(2):163-72.

6. Salda LT, Parquet MD, Matias RR, Natividad FF, Kobayashi N, Morita K. Molecular epidemiology of dengue 2 viruses in the Philippines: genotype shift and local evolution. Am J Trop Med Hyg. 2005;73(4):796-802.

7. Zhang C, Mammen Jr MP, Chinnawirotpisan P, Klungthong C, Rodpradit P, Monkongdee P, Nimmannitya S, Kalayanarooj S, Holmes EC. Clade replacements in dengue virus serotypes 1 and 3 are associated with changing serotype prevalence. J Virol. 2005;79(24):15123-30.

8. Klungthong C, Zhang C, Mammen Jr MP, Ubol S, Holmes EC. The molecular epidemiology of dengue virus serotype 4 in Bangkok, Thailand. Virology. 2004;329(1):168-79.

9. Wittke $\mathrm{V}$, Robb TE, Thu HM, Nisalak A, Nimmannitya S, Kalayanrooj S, Vaughn DW, Endy TP, Holmes EC, Aaskov JG. Extinction and rapid emergence of strains of dengue 3 virus during an interepidemic period. Virology. 2002;301(1):148-56.

10. Armstrong PM, Rico-Hesse R. Efficiency of dengue serotype 2 virus strains to infect and disseminate in Aedes aegypti. Am J Trop Med Hyg. 2003;68(5):539-44.

11. Messer WB, Gubler DJ, Harris E, Sivananthan K, de Silva AM. Emergence and global spread of a dengue serotype 3, subtype III virus. Emerg Infect Dis. 2003;9(7):800-9.

12. Bennett SN, Holmes EC, Chirivella M, Rodriguez DM, Beltran M, Vorndam V, Gubler DJ, McMillan WO. Molecular evolution of dengue 2 virus in Puerto Rico: positive selection in the viral envelope accompanies clade reintroduction. J Gen Virol. 2006:87(Pt 4):885-93.

13. Vu TT, Holmes EC, Duong V, Nguyen TQ, Tran TH, Quail M, Churcher C, Parkhill J, Cardosa J, Farrar J, et al. Emergence of the Asian 1 genotype of dengue virus serotype 2 in viet nam: in vivo fitness advantage and lineage replacement in South-East Asia. PLoS Negl Trop Dis. 2010;4(7):e757.
14. Duong V, Simmons C, Gavotte L, Viari A, Ong S, Chantha N, Lennon NJ, Birren BW, Vong S, Farrar JJ, et al. Genetic diversity and lineage dynamic of dengue virus serotype 1 (DENV-1) in Cambodia. Infect Genet Evol. 2013;15:59-68.

15. Holmes EC. Patterns of intra- and interhost nonsynonymous variation reveal strong purifying selection in dengue virus. J Virol. 2003;77(20):11296-8.

16. Nisalak A, Endy TP, Nimmannitya S, Kalayanarooj S, Thisayakorn U, Scott RM, Burke DS, Hoke CH, Innis BL, Vaughn DW. Serotype-specific dengue virus circulation and dengue disease in Bangkok, Thailand from 1973 to 1999. Am J Trop Med Hyg. 2003;68(2):191-202.

17. Anderson JR, Rico-Hesse R. Aedes aegypti vectorial capacity is determined by the infecting genotype of dengue virus. Am J Trop Med Hyg. 2006;75(5):886-92.

18. Armstrong PM, Rico-Hesse R. Differential susceptibility of Aedes aegypti to infection by the American and Southeast Asian genotypes of dengue type 2 virus. Vector Borne Zoonotic Dis. 2001;1(2):159-68.

19. Hanley KA, Nelson JT, Schirtzinger EE, Whitehead SS, Hanson CT. Superior infectivity for mosquito vectors contributes to competitive displacement among strains of dengue virus. BMC Ecol. 2008;8:1.

20. Gubler DJ, Nalim S, Tan R, Saipan H, Sulianti Saroso J. Variation in susceptibility to oral infection with dengue viruses among geographic strains of Aedes aegypti. Am J Trop Med Hyg. 1979;28(6):1045-52.

21. Vaughn DW, Green S, Kalayanarooj S, Innis BL, Nimmannitya S, Suntayakorn S, Endy TP, Raengsakulrach B, Rothman AL, Ennis FA, et al. Dengue viremia titer, antibody response pattern, and virus serotype correlate with disease severity. J Infect Dis. 2000;181(1):2-9.

22. Nguyet MN, Duong $T H$, Trung VT, Nguyen $T H$, Tran $C N$, Long VT, le Dui $T$, Nguyen HL, Farrar JJ, Holmes EC, et al. Host and viral features of human dengue cases shape the population of infected and infectious Aedes aegypti mosquitoes. Proc Natl Acad Sci U S A. 2013;110(22):9072-7.

23. Lambrechts L, Chevillon C, Albright RG, Thaisomboonsuk B, Richardson JH, Jarman RG, Scott TW. Genetic specificity and potential for local adaptation between dengue viruses and mosquito vectors. BMC Evol Biol. 2009;9:160.

24. Brathwaite Dick O, San Martin JL, Montoya RH, del Diego J, Zambrano B, Dayan GH. The history of dengue outbreaks in the Americas. Am J Trop Med Hyg. 2012;87(4):584-93.

25. Fouque F, Garinci R, Gaborit P. Epidemiological and entomological surveillance of the co-circulation of DEN-1, DEN-2 and DEN-4 viruses in French Guiana. Trop Med Int Health. 2004;9(1):41-6.

26. Reynes JM, Laurent A, Deubel V, Telliam E, Moreau JP. The first epidemic of dengue hemorrhagic fever in French Guiana. Am J Trop Med Hyg. 1994;51(5):545-53.

27. Dussart P, Lavergne A, Lagathu G, Lacoste V, Martial J, Morvan J, Cesaire R. Reemergence of dengue virus type 4, French Antilles and French Guiana, 2004-2005. Emerg Infect Dis. 2006;12(11):1748-51.

28. L'Azou M, Taurel AF, Flamand C, Quenel P. Recent epidemiological trends of dengue in the French territories of the Americas (2000-2012): a systematic literature review. PLoS Negl Trop Dis. 2014;8(11):e3235.

29. Rico-Hesse R. Microevolution and virulence of dengue viruses. Adv Virus Res. 2003;59:315-41.

30. Cologna R, Armstrong PM, Rico-Hesse R. Selection for virulent dengue viruses occurs in humans and mosquitoes. J Virol. 2005;79(2):853-9.

31. Lambrechts L, Fansiri T, Pongsiri A, Thaisomboonsuk B, Klungthong C, Richardson $J$ H, Ponlawat A, Jarman RG, Scott TW. Dengue-1 virus clade replacement in Thailand associated with enhanced mosquito transmission. J Virol. 2012;86(3):1853-61.

32. Thavara U, Siriyasatien P, Tawatsin A, Asavadachanukorn P, Anantapreecha S, Wongwanich R, Mulla MS. Double infection of heteroserotypes of dengue viruses in field populations of Aedes aegypti and Aedes albopictus (Diptera: Culicidae) and serological features of dengue viruses found in patients in southern Thailand. Southeast Asian J Trop Med Public Health. 2006:37(3):468-76.

33. Pessanha JE, Caiaffa WT, Cecilio AB, Iani FC, Araujo SC, Nascimento JC, Kroon EG, Proietti FA, Arias JR. Cocirculation of two dengue virus serotypes in individual and pooled samples of Aedes aegypti and Aedes albopictus larvae. Rev Soc Bras Med Trop. 2011;44(1):103-5.

34. Bharaj P, Chahar HS, Pandey A, Diddi K, Dar L, Guleria R, Kabra SK, Broor S. Concurrent infections by all four dengue virus serotypes during an outbreak of dengue in 2006 in Delhi, India. Virol J. 2008;5:1.

35. Pongsiri $P$, Themboonlers A, Poovorawan $Y$. Changing pattern of dengue virus serotypes in Thailand between 2004 and 2010. J Health Popul Nutr. 2012;30(3):366-70.

36. Figueiredo RM, Naveca FG, Oliveira CM, Bastos Mde S, Mourao MP, Viana Sde S, Melo Mdo N, Itapirema EF, Saatkamp CJ, Farias IP. Co-infection of Dengue virus by serotypes 3 and 4 in patients from Amazonas, Brazil. Rev Inst Med Trop Sao Paulo. 2011;53(6):321-3. 
37. Gubler DJ, Kuno G, Sather GE, Waterman SH. A case of natural concurrent human infection with two dengue viruses. Am J Trop Med Hyg. 1985;34(1):170-3.

38. Kuberski $\Pi$, Rosen $L$. A simple technique for the detection of dengue antigen in mosquitoes by immunofluorescence. Am J Trop Med Hyg. 1977;26(3):533-7.

39. Mousson L, Zouache K, Arias-Goeta C, Raquin V, Mavingui P, Failloux AB. The native Wolbachia symbionts limit transmission of dengue virus in Aedes albopictus. PLoS Negl Trop Dis. 2012;6(12):e1989.

40. Aaskov J, Buzacott K, Field E, Lowry K, Berlioz-Arthaud A, Holmes EC. Multiple recombinant dengue type 1 viruses in an isolate from a dengue patient. J Gen Virol. 2007;88(Pt 12):3334-40.

41. Craig S, Thu HM, Lowry K, Wang XF, Holmes EC, Aaskov J. Diverse dengue type 2 virus populations contain recombinant and both parental viruses in a single mosquito host. J Virol. 2003;77(7):4463-7.

42. Tolou HJ, Couissinier-Paris P, Durand JP, Mercier V, de Pina JJ, de Micco P, Billoir F, Charrel RN, de Lamballerie X. Evidence for recombination in natural populations of dengue virus type 1 based on the analysis of complete genome sequences. J Gen Virol. 2001;82(Pt 6):1283-90.

43. Worobey M, Rambaut A, Holmes EC. Widespread intra-serotype recombination in natural populations of dengue virus. Proc Natl Acad Sci U S A. 1999;96(13)::7352-7.

44. Villabona-Arenas CJ, de Brito AF, de Andrade Zanotto PM. Genomic mosaicism in two strains of Dengue virus type 3. Infect Genet Evol. 2013;18:202-12.

45. Li D, Lott WB, Lowry K, Jones A, Thu HM, Aaskov J. Defective interfering viral particles in acute dengue infections. PLoS One. 2011;6(4):e19447.

46. Lorono-Pino MA, Cropp CB, Farfan JA, Vorndam AV, Rodriguez-Angulo EM, Rosado-Paredes EP, Flores-Flores LF, Beaty BJ, Gubler DJ. Common occurrence of concurrent infections by multiple dengue virus serotypes. Am J Trop Med Hyg. 1999;61(5):725-30.

47. Wang WK, Chao DY, Lin SR, King CC, Chang SC. Concurrent infections by two dengue virus serotypes among dengue patients in Taiwan. J Microbiol Immunol Infect. 2003;36(2):89-95.

48. Sabchareon A, Lang J, Chanthavanich P, Yoksan S, Forrat R, Attanath P, Sirivichayakul C, Pengsaa K, Pojjaroen-Anant C, Chokejindachai W, et al. Safety and immunogenicity of tetravalent live-attenuated dengue vaccines in Thai adult volunteers: role of serotype concentration, ratio, and multiple doses. Am J Trop Med Hyg. 2002;66(3):264-72.

\section{Submit your next manuscript to BioMed Central and we will help you at every step:}

- We accept pre-submission inquiries

- Our selector tool helps you to find the most relevant journal

- We provide round the clock customer support

- Convenient online submission

- Thorough peer review

- Inclusion in PubMed and all major indexing services

- Maximum visibility for your research

Submit your manuscript at www.biomedcentral.com/submit

) Biomed Central 